\title{
Modelo de concepção e avaliação da estratégia de territórios*
}

\author{
Hugo Santana de Figueirêdo Junior** \\ Mônica Cavalcanti Sá de Abreu***
}

Sumário: 1. Introdução; 2. Conceitos de estratégia; 3. Modelo de competitividade territorial; 4. Aplicação do modelo a um território: o Centro de Fortaleza; 5. Diretrizes para o desenvolvimento do Centro de Fortaleza; 6. Conclusões.

Summary: 1 . Introduction; 2. Concepts of strategy; 3 . Territorial competitiveness model; 4. Using the model in a territory: Downtown Fortaleza; 5. Guidelines for the development of Downtown Fortaleza; 6. Conclusions.

Palavras-chave: estratégia; competitividade territorial; planejamento regional; desenvolvimento local; gestão pública.

KEY WORDs: strategy; territorial competitiveness; regional planning; local development; public management.

Este artigo apresenta um modelo de concepção e avaliação de estratégia de territórios, desenvolvido a partir da expansão do modelo ECP (estrutura-conduta-performance) utilizado para empresas. O modelo, denominado ECP territorial, é aplicado ao Centro de Fortaleza, área que, assim como várias outras regiões centrais de cidades de grande porte em todo o mundo, enfrenta um processo acelerado de esvaziamento e demanda uma revitalização sustentável. O artigo analisa a competitividade da região e identifica oportunidades estratégicas de desenvolvimento, baseadas no suporte a setores econômicos nos quais o Centro possui vantagens. Os resultados comprovam

\footnotetext{
* Artigo recebido em jan. 2007 e aceito em ago. 2008.

** Master in business administration pelo Rensselaer Polytechnic Institute (EUA). Professor assistente da Faculdade de Economia, Administração, Atuária e Contabilidade (Feaac), Departamento de Contabilidade, Universidade Federal do Ceará (UFC). Endereço: Av. da Universidade, 2431 — CEP 60020-180, Fortaleza, CE, Brasil. E-mail: hugo.figueiredo@ufc.br.

*** Doutora em engenharia de produção pela Universidade Federal de Santa Catarina (EPS/UFSC). Professora adjunta da Faculdade de Economia, Administração, Atuária e Contabilidade (Feaac), Departamento de Administração de Empresa, Universidade Federal do Ceará (UFC). Endereço: Av. da Universidade, 2431 - CEP 60020-180, Fortaleza, CE, Brasil. E-mail: mabreu@ufc.br.
} 
a utilização do modelo ECP territorial para o planejamento de estratégias de bairros e sugerem a sua aplicação para territórios em geral.

\section{Strategy formulation and assessment model for territories}

This article presents a strategy formulation and assessment model for territories, conceived from the expansion of the SCP (structure-conduct-performance) model used for strategic planning of businesses in general. In order to be validated, the territorial SCP model was deployed in Downtown Fortaleza, Brazil. Like many other central neighborhoods of large cities around the world, Downtown Fortaleza faces an accelerated decay process and urgently calls for a sustainable restoration. The article analyzes the area's competitiveness and identifies development opportunities based on the support to economic sectors in which Downtown have advantages. The results reinforce the use of the territorial SCP model as a strategic planning tool for neighborhoods and suggest the model can be applied to territories in general.

\section{Introdução}

O processo de planejamento estratégico de territórios, e de cidades em particular, vem sendo empregado em vários países a partir dos conceitos primordiais de estratégia, derivados da prática militar (Güell, 1997), e pode ser aprimorado, em face de novas metodologias empresariais com ênfase na análise de competitividade, e adaptado para a realidade nacional. Nesse contexto, pretende-se expandir os modelos de estratégia empresarial, fundamentados na avaliação de competitividade, para aplicação na definição de estratégias sustentáveis de desenvolvimento de territórios.

A elaboração do modelo de competitividade territorial ocorre a partir de pesquisa bibliográfica sobre modelos de estratégia aplicados a empresas e a regiões, da organização das diversas variáveis de análise, e da consolidação de uma proposta de modelo.

A validação do modelo de competitividade territorial se dá com a preparação dos instrumentos de coleta dos dados, da definição do território amostral (como parte de um projeto específico para o Centro de Fortaleza), e da busca dos dados quantitativos e qualitativos em fontes primárias e secundárias (incluindo a participação de indivíduos e grupos de interesses locais).

A conclusão se faz a partir da organização e do processamento dos dados, da análise crítica dos resultados do modelo aplicada à realidade do território analisado, da confirmação do alcance dos objetivos pretendidos e do estabelecimento de possibilidades de expansão do modelo para territórios em geral. 


\section{Conceitos de estratégia}

Estratégia, como conceito básico derivado das operações militares, refere-se aos meios para se atingir um determinado objetivo. Assim, planejamento estratégico é simplesmente o processo de determinação da estratégia a ser seguida. O modelo de planejamento estratégico mais empregado nos negócios, quando do surgimento do campo de estudo, adotava uma sequência semelhante à empregada pelas ciências militares, de onde se originou: a identificação da missão; a análise de ambiente externo; a análise do ambiente interno; a análise de forças e fraquezas da entidade; as oportunidades e ameaças para a entidade. O resultado do planejamento estratégico é um conjunto de diretrizes estratégicas de caráter qualitativo que orientam a entidade no planejamento operacional.

Com a evolução das ciências administrativas, modificações significativas foram introduzidas no processo. Assim, vários modelos têm sido empregados no desenvolvimento de estratégias vencedoras para empresas, como o clássico modelo de análise de forças da indústria (Porter, 1980), e o modelo estrutura-conduta-performance (ECP) (Scherer e Ross, 1990), concebido a partir de trabalhos originais de Edward Mason e Joseph Bain em meados do século passado. Mais recentemente, percebeu-se a necessidade de haver distinção de processos de planejamento entre entidades que visam ao lucro e entidades que não visam ao lucro (Kaplan, 2001).

Entidades que visam ao lucro têm, por definição, a sua missão primordial bem definida, qual seja, obter elevados retornos sobre o capital empregado de seus acionistas. Qualquer empresa que tenha missão diferente dessa está fadada a correr risco de sobrevivência (Porter, 2001). Tal orientação se aplica mesmo no ambiente atual, em que as empresas são avaliadas pelo seu desempenho social e ambiental, além do desempenho econômico. E não quer dizer também que a empresa deva buscar o lucro de qualquer forma, pelo contrário, deverá sempre se basear na visão (aspirações) e nos valores de seus acionistas e gestores. Assim, para as entidades que visam ao lucro, planejamento estratégico significa selecionar, escolher dinamicamente produtos/serviços e mercados e adequar a entidade para entregar esses produtos/serviços de forma consistente, a fim de obter uma posição competitiva e duradoura.

Fazendo um paralelo entre a nomenclatura atual e a tradicional, o processo de seleção de produtos e mercados passa pela análise estática e dinâmica (cenários) da estrutura competitiva dos setores de atuação da entidade (ambiente externo, oportunidades e ameaças), e a adequação da entidade para entregar esses produtos/serviços aos seus clientes passa pela análise de todas as suas atividades de agregação de valor (ambiente interno, forças e fraquezas). 
No caso de entidades não lucrativas, a etapa de identificação da missão é mais relevante, pois esta sofre de uma tendência à falta de clareza e ainda pode se alterar se ocorrerem mudanças no ambiente externo. Mesmo assim, a seleção de produtos/serviços e mercados permanece como base do processo de planejamento estratégico. É importante ressaltar, porém, que o resultado econômico, se existir, passa a ser um meio para o alcance da missão, e não um fim. E que, em substituição ao lucro, devem ser estabelecidos fins quantificáveis para avaliar o alcance da missão (Sawhill e Williamson, 2001).

Quando a entidade não lucrativa é um território, definido como um espaço físico limitado por fronteiras, habitado e organizado sob algum tipo de gestão governamental, percebe-se a carência de ferramentas para auxiliar o processo de definição de estratégias. Nesse sentido, sobressai o modelo do diamante para auxiliar nações e outras regiões em geral (Porter, 1999), baseado no conceito de competitividade, mas que ainda apresenta limitações em comparação ao desenvolvimento de um modelo ampliado de estratégia territorial.

Em geral, o modelo do diamante permite uma avaliação da competitividade de um determinado território de forma bem detalhada, contudo seu emprego isolado tende a sublevar a visão integrada de conjunto de territórios que só um modelo de competitividade mais transversal quanto à comparação e à interação entre concorrentes permite. Além disso, o modelo do diamante não explicita os objetivos de performance que determinado território deve almejar e é reticente quanto ao impacto de intervenções espaciais estruturadoras, por exemplo, na competitividade dos territórios, preferindo focar na situação estática do ambiente competitivo.

\section{O modelo ECP: estrutura-conduta-performance}

O modelo ECP - estrutura-conduta-performance (Scherer e Ross, 1990) permite estabelecer a estratégia de uma empresa que busca atingir uma performance econômica superior, e está fundamentado no conceito de causalidade, partindo da premissa de que as empresas operam em uma estrutura de mercado aberto. No sistema de mercado aberto, os vendedores e os consumidores atuam em resposta aos sinais dos preços, gerados pela interferência da oferta e da demanda.

A concepção do modelo ECP tem, como princípio básico, que a performance de uma empresa é o reflexo de suas práticas competitivas ou padrões 
de conduta que, por sua vez, dependem da estrutura de mercado em que a empresa está inserida (figura 1). O ambiente da estrutura da indústria pode oscilar entre cooperação e rivalidade, de acordo com as práticas comerciais de cada um de seus participantes. Esse modelo incorpora choques externos (eventos significativos oriundos principalmente de inovações tecnológicas, da ação governamental, de novos entrantes e de mudanças no comportamento social) como elementos dinâmicos para analisar a sua influência na estrutura da indústria, na conduta dos participantes e, consequentemente, na performance deles (Copeland, Koller e Murrin, 1994).

Figura 1

Modelo ECP: estrutura-conduta-performance

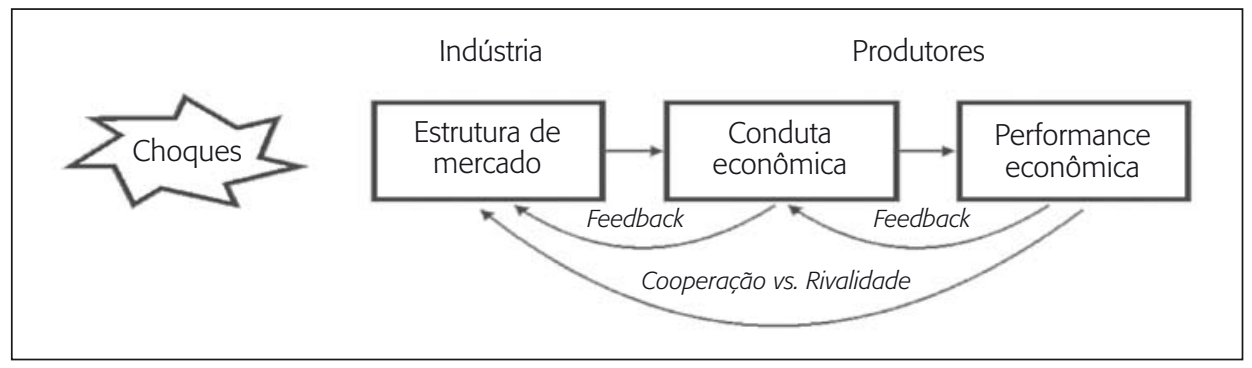

Fonte: Copeland, Koller e Murrin, 1994.

Para analisar a estrutura do mercado em que compete a empresa, são usados indicadores de comportamento da demanda e da oferta. Para conduta, utiliza-se o comportamento da empresa e seus competidores ao longo de todo o seu sistema de negócios, desde a aquisição de matéria-prima e insumos até a entrega do produto acabado aos clientes. Quanto à performance, empregamse indicadores relacionados ao objetivo principal da empresa, o retorno econômico aos acionistas. Com o advento da preocupação social e ambiental das empresas, esse modelo foi expandido para incorporar objetivos mais amplos (Abreu, Figueirêdo e Varvakis, 2004). Contudo, sua utilização tem permanecido restrita às empresas.

\section{Os indicadores governamentais}

Umas das questões básicas na análise das estratégias territoriais é que indicadores utilizar para avaliar as estratégias. Pode-se, por exemplo, avaliar a 
ação dos governos através de três componentes: os indicadores de insumo, os indicadores de produto e os indicadores de resultado (Rio Grande do Sul, 2005).

Os indicadores de insumo são os que apresentam a disponibilidade de alocação de recursos financeiros para as estratégias que afetam a realidade do território; já os indicadores de produto são indicadores intermediários, que traduzem em medidas quantitativas o esforço operacional dos territórios na oferta de bens e serviços públicos à população. Já os indicadores de resultado são os vinculados diretamente à realidade social dos territórios e são medidas que retratam os resultados efetivos das estratégias territoriais, focadas nas condições de vida da população nas áreas de saúde, educação, trabalho e renda, entre outros. A relação entre os indicadores de insumo e de produto revela a eficiência com que os recursos governamentais são empregados e a relação entre os indicadores de insumo e de resultado revela a eficácia do emprego dos recursos governamentais.

Embora focados na gestão governamental, esse princípio de classificação de indicadores de gestão pode ser empregado para incluir a participação não governamental e outros aspectos qualitativos, tão presentes na gestão dos territórios.

\section{Modelo de competitividade territorial}

Nos territórios, limitados geograficamente como países, estados, municípios ou mesmo bairros, os objetivos certamente são diferentes daqueles das empresas privadas, e estão genericamente associados ao desenvolvimento econômico e social e, mais recentemente, ao equilíbrio ambiental. Porém, tais territórios, em um ambiente de recursos limitados, também competem uns com os outros para trazer mais benefícios às populações. A definição da missão básica do território como o alcance do desenvolvimento econômico e social com equilíbrio ambiental pode parecer um clichê, mas há maneiras de verificar se essa missão está sendo alcançada por meio de indicadores quantitativos selecionados. Alguns desses indicadores de desempenho têm sido largamente aceitos e condensados em índices como o índice de desenvolvimento humano, IDH (Pnud, 2004).

Entretanto, as estratégias que permitem um território ser bem-sucedido também passam por escolher onde e como competir - através das empresas localizadas em sua área - em determinados setores econômicos, 
por meio da identificação e do aprimoramento de suas vantagens competitivas setoriais, que dependem de um processo altamente localizado. Ao final, é a maior competitividade de um território que traz a prosperidade para o conjunto dos seus habitantes.

Com o propósito de identificar estratégias que permitam desenvolver um determinado território, concebeu-se o modelo ECP territorial, adaptando-se o modelo estrutura-conduta-performance (ECP) para a análise de territórios em geral, e de bairros em particular. O modelo ECP territorial é inicialmente concebido para bairros, unidades político-geográficas dos municípios, mas pode ser ampliado, com algumas adaptações, para qualquer região composta por sub-regiões (conjunto de municípios) ou integrantes de suprarregiões (conjunto de estados ou conjunto de países).

O termo território aqui empregado vai além da simples conotação de espaço delimitado, inclui sua organização gerencial, sua integração com outras entidades externas às suas fronteiras e seus habitantes, com suas atividades e os laços existentes entre eles. Pode ser associado ao conceito clássico de região (Kayser, 1966).

\section{ECP territorial: um modelo de estratégia de territórios}

A compreensão específica da estrutura dos setores econômicos que sustentam os territórios, da conduta que os territórios adotam para conseguir um bom desempenho econômico e social com equilíbrio ambiental, e do desempenho efetivo dos territórios, podem revelar padrões de conduta vencedores e embasar a concepção de estratégias para um território específico, e são sumarizadas no modelo ECP territorial (figura 2).

A lógica é que, conhecendo as características do território, e em particular do bairro em questão, o ambiente competitivo em que este está inserido e suas vantagens competitivas, é possível delinear a situação futura desejada para a concretização de seu desenvolvimento econômico sustentável com justiça social e equilíbrio ambiental, objetivo final do território.

Da mesma forma que no modelo ECP, existem também realimentações internas entre performance e conduta dos territórios e estrutura do mercado dos setores em que estes territórios competem, assim como a possibilidade de cooperação e rivalidade entre os territórios. Essas interações, juntamente com choques externos, conferem uma dinamicidade própria do modelo ECP territorial. 


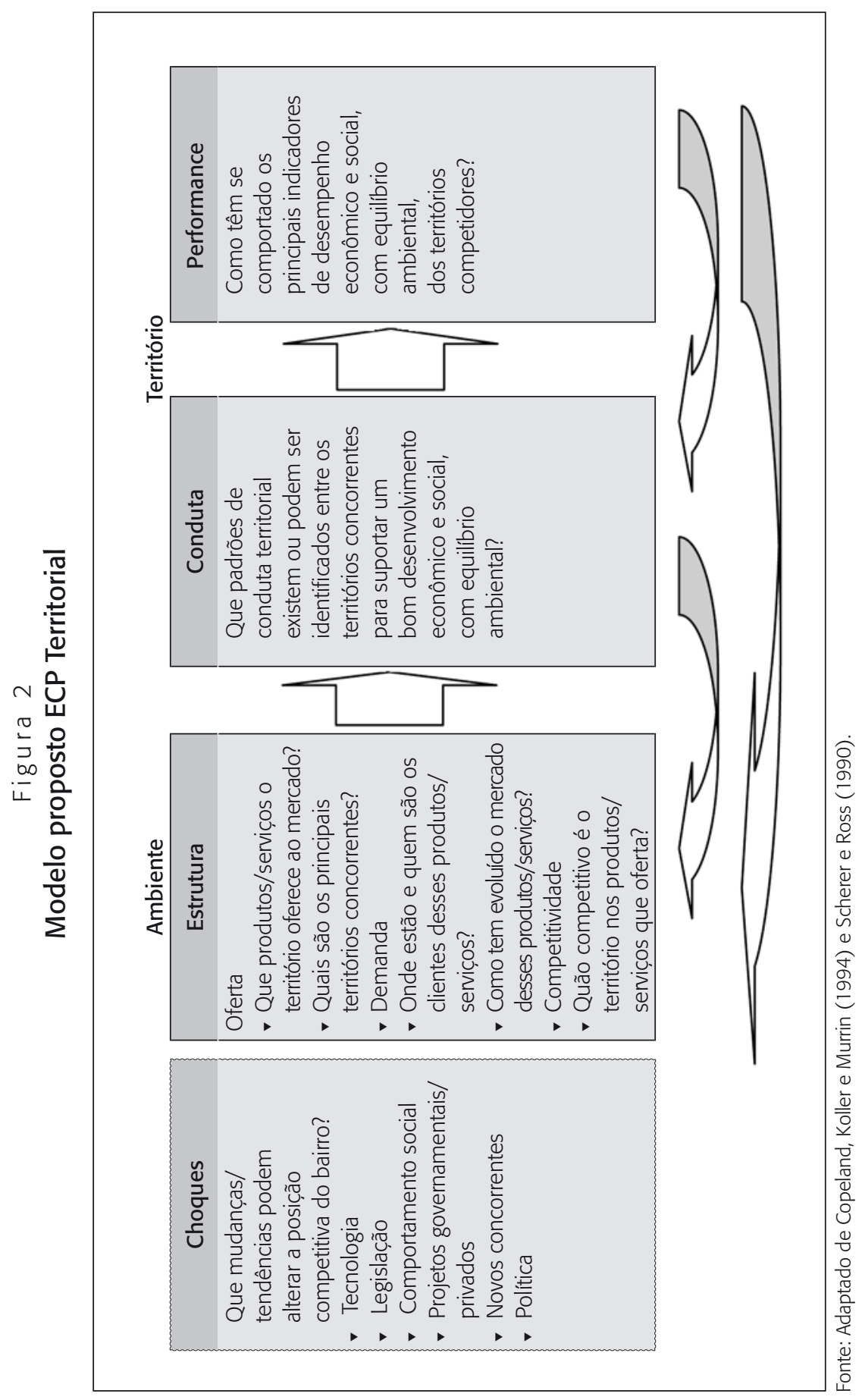




\section{Indicadores de estrutura territorial}

A referência à estrutura territorial no modelo ECP territorial está relacionada à estrutura de mercado de cada um dos setores que compõem a economia do território, e suas condições de oferta (quantidade e custo dos fatores, qualidade e especialização dos fatores, arranjos intersetoriais, concentração de empresas produtoras, disponibilidade de produtos substitutos, barreira de entrada/saída etc.) e de demanda (quantidade e concentração espacial de clientes, comportamento dos clientes, taxas de crescimento, volatilidade/ciclicalidade etc.) nesse território em comparação às condições de oferta globais, para determinar quão competitivo é um determinado setor na oferta de seus produtos e serviços a partir do território em análise.

Como os territórios são unidades espacialmente limitadas cujos setores competem em um mercado livre, deve-se destacar a circulação das mercadorias e serviços entre suas fronteiras de forma a compreender o fluxo de recursos e a capacidade de cada um de atrair mais ou menos divisas. Os preços dos produtos de cada setor, por sua vez, devem refletir o equilíbrio das condições de oferta e de demanda setoriais. É também importante identificar, se existir, algum grau de hierarquia entre os territórios competidores, conforme a função desempenhada por eles no grupo (centralidade, metrópole etc.) (Güell, 1997).

\section{Indicadores de conduta territorial}

Da mesma forma que as empresas apresentam vários elementos no seu sistema de negócios, por exemplo, pesquisa e desenvolvimento, compras, produção, distribuição, vendas (Porter, 1980), os territórios também podem ser vistos como possuidores de elementos de sistemas territoriais para o alcance de seus objetivos.

O ponto de partida para a compreensão da conduta de um território é composição do seu sistema territorial, aqui representado por cinco grandes elementos ou bases territoriais - urbana/demográfica, natural, social, econômica e institucional - abrangendo os aspectos e as variáveis de controle necessários para acompanhar minuciosamente os impactos provocados por cada uma das estratégias definidas (quadro 1).

Tal segmentação guarda certa semelhança com a abordagem do sistema homem-natureza (Chadwick, 1973), em que o sistema é composto por quatro partes: o ecossistema, o sistema de espaços adaptados pelo homem, o sistema 
de atividades do homem e o sistema de valores do homem. A diferença é que o homem, por interferir deliberadamente e em larga escala na natureza, é considerado elemento particular do ecossistema, assim como as adaptações por ele feitas, e as atividades do homem são desmembradas em econômicas e sociais.

\section{Quadro 1 \\ Elementos formadores de um território}

\begin{tabular}{|ll|}
\hline Base do sistema territorial & \multicolumn{1}{c|}{ Aspectos } \\
\hline $\begin{array}{l}\text { Natural: espaço do território sobre o qual se } \\
\text { estabelecem os habitantes }\end{array}$ & $\begin{array}{l}\text { Posição geográfica, relevo, solo, clima, recursos } \\
\text { naturais }\end{array}$ \\
$\begin{array}{l}\text { Urbana/demográfica: habitantes e forma de } \\
\text { ocupação do espaço natural do território }\end{array}$ & $\begin{array}{l}\text { População, domicílios e infraestrutura de } \\
\text { serviços }\end{array}$ \\
$\begin{array}{l}\text { Econômica: atividades econômicas que se } \\
\text { desenrolam no território }\end{array}$ & Produto interno bruto (PIB), emprego \\
$\begin{array}{l}\text { Social: serviços sociais que se desenrolam no } \\
\text { território }\end{array}$ & Saúde, educação, lazer e segurança \\
$\begin{array}{l}\text { Institucional: forma de gestão pública e privada } \\
\text { e valores comuns que unem os habitantes do } \\
\text { território entre si e ao espaço ocupado }\end{array}$ & \begin{tabular}{l} 
Pública: finanças, organização. Privada: \\
\hline
\end{tabular} \\
\hline
\end{tabular}

Como parte da conduta do modelo ECP territorial, foi definida uma série de indicadores para representar cada uma das bases que compõem o território, ou já no caso específico, dos bairros e do município. Dois critérios foram utilizados na escolha desses indicadores:

v os indicadores devem ser medidas das ferramentas ou alavancas que os bairros e o município podem manejar em cada uma das bases para alcançar seu desenvolvimento econômico e social sustentável;

v os indicadores devem estar disponíveis para comparação, no mesmo período de tempo, entre os bairros e o município, e eventualmente para comparação entre municípios e regiões do estado a que pertencem e de outros estados e países.

Embora esse conjunto de indicadores espelhe uma realidade representativa dos bairros e do município, vale ressaltar que a comparação intramunicipal não deve se restringir a esses indicadores, mas também considerará aspectos 
qualitativos importantes que fazem parte das bases dos bairros e do município, mas que não podem ser expressos quantitativamente. Por exemplo, enquanto condições de demanda, oferta e setores correlatos e de apoio definidos no modelo do diamante (Porter, 1999) podem ser compreendidos como elementos de estrutura territorial, o contexto para estratégia e rivalidade é eminentemente um elemento da conduta territorial, de caráter institucional. Ademais, alguns aspectos podem ter se modificado desde a data de comparação até a atual, de maneira que estas mudanças serão consideradas sempre que relevantes.

Assim, para estabelecer a situação atual dos bairros, obter uma visão agregada do município e comparar a sua situação atual com a de seus principais concorrentes, a fim de subsidiar a identificação de suas vantagens competitivas, foram escolhidos indicadores dos diversos aspectos do bairro e do município. Alguns desses indicadores guardam semelhança com os indicadores de produto da gestão governamental, visto que é através deles que o setor público se manifesta na contribuição para implementação das estratégias dos territórios (quadro 2).

\section{Quadro 2}

\section{Indicadores quantitativos de comparação intrabairros}

\begin{tabular}{|c|c|}
\hline Base do sistema territorial & Indicador \\
\hline Urbana/demográfica & $\begin{array}{l}\text { - População } \\
\text { - Densidade demográfica } \\
\text { - Taxa média anual de crescimento populacional } \\
\text { - Abastecimento de água } \\
\text { - Coleta de lixo }\end{array}$ \\
\hline Institucional & $\begin{array}{l}\text { - Número de entidades associativas/habitante } \\
\text { - Receita orçamentária própria/receita própria total do município }\end{array}$ \\
\hline Social & $\begin{array}{l}\text { - Número de salas de aula/habitante } \\
\text { - Número de professores/aluno } \\
\text { - Número de leitos/habitante } \\
\text { - Número de consultas médicas/habitante }\end{array}$ \\
\hline Econômica & $\begin{array}{l}\text { \% do setor primário nos empregos local/municipal } \\
\text { \% do setor secundário nos empregos local/municipal } \\
\text { - \% do setor terciário nos empregos local/municipal }\end{array}$ \\
\hline
\end{tabular}

A base natural cobre apenas aspectos qualitativos como a própria localização geográfica de cada bairro, visto que os bairros são áreas totalmente urbanizadas e que outros aspectos naturais como clima, solo, subsolo e 
reservas hídricas não são diferenciadores de competitividade territorial no município. Caso haja informações quantitativas disponíveis, pode-se analisar a vegetação, sob o enfoque de áreas verdes destinadas ao uso humano em cada bairro.

A base urbana/demográfica engloba os aspectos da evolução e da distribuição espacial da população além de seu tamanho absoluto, e os aspectos de cobertura de infraestrutura. Já a base social trata de indicadores de cobertura de educação e saúde. Eventualmente poderia ser incluído um indicador abrangente, como número de policiais civis e militares por habitante, para avaliar a cobertura de segurança dos bairros e do município, porém é comum não se identificar fontes de consulta atualizadas e representativas.

Para a base econômica, foram escolhidas as participações dos setores econômicos no número de empregos formais dos bairros e do município, como revelador da forma de atuação local e municipal. A base institucional, por sua vez, divide-se em pública e privada. Para avaliar a pública, foi utilizado um indicador de arrecadação de receita própria do bairro em relação à receita própria total do município, que reflete a saúde financeira do bairro. Para avaliar a base privada, foi utilizada a relação de entidades de classe por habitante para indicar o grau de participação popular no bairro, embora ciente que a qualidade da representação é mais importante que a quantidade.

\section{Indicadores de performance territorial}

Finda a comparação da conduta dos concorrentes sobre as ferramentas componentes das bases territoriais, parte-se para a comparação da performance do bairro e seus concorrentes, que poderá ser diferenciada pela atuação distinta de cada um deles sobre as ferramentas. Posteriormente, devem ser apontados indicadores gerais de desenvolvimento econômico, social e ambiental, e possivelmente estabelecidos prognósticos quanto a esses indicadores, a partir de uma situação atual diagnosticada e considerando o efeito das propostas apresentadas, para permitir a avaliação integrada dos seus resultados.

Como parâmetros para aferir o desenvolvimento econômico e social de um território, ou bairro em particular, devem ser escolhidos indicadores que sejam regularmente acompanhados e facilmente disponíveis por bairros e que tragam certa semelhança com aqueles utilizados na formação do IDH:

- PIB per capita - indica o grau de desenvolvimento da economia e sua distribuição média; 
- combinação da taxa de analfabetismo - indica o grau de instrução da população adulta, e da taxa de matrícula - indica o percentual da população em idade escolar matriculada;

- expectativa de vida ao nascer - indica a idade média esperada que cada indivíduo deve alcançar.

Repare que o próprio IDH, ao utilizar o PIB per capita, trata a questão econômica como média e não aborda a desigualdade, que poderia ser incorporada pelo uso do índice de Gini-renda, que indica o grau de distribuição equitativa da renda e varia de zero a um, sendo zero igualdade absoluta e um desigualdade absoluta (Iplance, 2000). E os demais indicadores são referentes apenas ao desempenho social (mais especificamente educação e saúde).

Além desses indicadores de performance, seria possível acrescentar um de segurança como número de crimes por habitante, para medir o grau de segurança da população, caso disponível. Da mesma forma, para medir o desempenho ambiental, seria possível incluir indicadores de poluição no território, por compartimento ambiental (ar, água, solo, biota). Em qualquer das situações, é necessário atentar para que os indicadores selecionados estejam realmente relacionados à performance, objetivo final, e não à conduta, meio para o objetivo. Tais indicadores guardam semelhança com os indicadores gerais de resultado da gestão governamental, uma vez que expressam objetivos comuns dos habitantes do território.

\section{Choques externos}

As mudanças significativas que exigem alterações de conduta dos territórios, com reflexos na performance e na estrutura dos setores dos territórios são denominadas choques externos. Assim como no modelo ECP para empresas (Scherer, 1996), também conferem dinamismo ao modelo ECP territorial e podem advir de alterações em tecnologia, legislação, comportamento social, projetos governamentais/privados, novos territórios concorrentes e em política.

Por exemplo, a mudança no comando de instituições governamentais pode ser um choque externo de caráter político se tem o potencial de interferir na estabilidade de instituições e afetar um determinado setor do território. Ou um projeto governamental estruturador pode alterar significativamente a capacidade de oferta de outro setor, reposicionando o território no ambiente competitivo. 


\section{A definição das estratégias de desenvolvimento}

Para se construir bases sólidas para a montagem de estratégias de um bairro (ou subunidades territoriais em geral) dentro de um município (ou supraunidade territorial), é preciso que sejam considerados os caminhos e as aspirações delineados individualmente por cada bairro ou grupo de bairros do município, de forma a identificar eventuais conflitos e ressaltar possíveis concordâncias. Para isso, pode-se recorrer a ações acordadas e registradas pelos bairros, se existirem, consolidando um conjunto de propostas individuais já amadurecidas (planos estratégicos, planos de desenvolvimento municipal) com eventuais ajustes. Tal procedimento pode ser expandido para territórios em geral, sempre considerando a sua inserção em unidades espaciais maiores ou a sua divisão em unidades espaciais menores.

A partir da análise competitiva dos bairros e de suas vantagens e desvantagens, é possível definir as estratégias e as ações necessárias, o papel do bairro em questão na composição das estratégias globais no contexto municipal (hierarquia e função, com alocação preliminar de infraestrutura e serviços públicos locais), e o resultado obtido com essas medidas (quadro 3).

\section{Quadro 3}

\section{Questões para definir as estratégias de desenvolvimento}

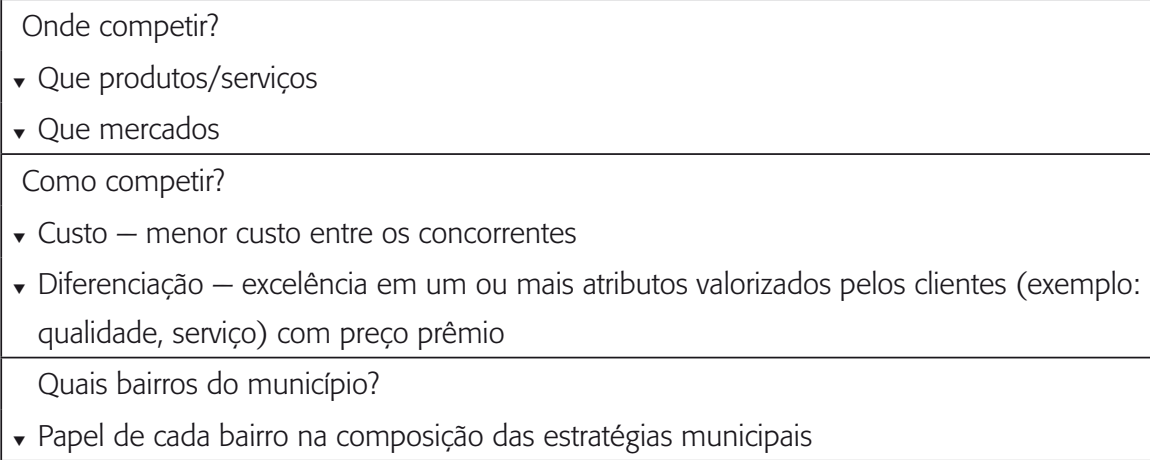

Nesta etapa de definição das estratégias de desenvolvimento, são consideradas as características peculiares do bairro, suas vantagens e limitações, para aproveitar as oportunidades e superar as ameaças visualizadas. Também deverão ser analisados cenários diante de eventuais choques externos que tenham o poder de modificar sensivelmente o ambiente competitivo. 
Por fim, deverão ser enfatizadas as questões relativas à preservação e ao controle ambiental, e as atividades econômicas com suas respectivas distribuições espaciais, de forma a permitir o fortalecimento da organização territorial do bairro, e a estabelecer roteiros para atração de investimentos que rompam com a estagnação e fortaleçam a base econômica, e consolidem o desenvolvimento da cidadania e do bem-estar social.

\section{Aplicação do modelo a um território: o Centro de Fortaleza}

Um caso exemplar onde essas novas metodologias de competitividade territorial podem ser utilizadas é o de desenvolvimento de bairros (apesar da limitação de estatísticas para bairros oferecer um grau adicional de dificuldade), e mais especificamente do soerguimento de bairros centrais. De fato, a revitalização de bairros centrais tem constado na agenda de gestores municipais por todo o país e mesmo pelo mundo. Iniciativas nesse sentido requerem comprometimento de longo prazo e têm sido buscadas em cidades brasileiras como São Paulo e Recife, nesta última iniciou-se em 1986 e encontra-se ainda em andamento (Zancheti, 2004).

Em Fortaleza, o debate sobre a revitalização do Centro tomou corpo a partir da década de 1990, sem que até o momento tenham sido identificadas alternativas que revertessem ou estacionassem um quadro evidente de decadência, mais emblemático quando se acompanha a perda contínua da sua população residente e da sua atividade econômica, logo, da sua vitalidade como bairro.

Na realidade, conforme os censos do Instituto Brasileiro de Geografia e Estatística (IBGE) de 1980 a 2000, percebe-se que o Centro vem perdendo população há algum tempo, a uma taxa negativa de 2,65\% ao ano entre $1991 \mathrm{e}$ 2000, apesar do município de Fortaleza ter sua população acrescida a uma taxa positiva de $2,17 \%$ ao ano no mesmo período. Apenas para registro, em 2000 o bairro registrava 24.775 habitantes versus 38.545 em 1980 (IBGE, 2001).

Na expressividade do declínio na participação relativa da população do Centro de Fortaleza em relação à capital, constatada no período 1980-2000, destacam-se como causas principais:

- o espraiamento físico da área urbanizada da cidade de Fortaleza, pelo rápido crescimento populacional aliado à precariedade do planejamento urbano e à especulação imobiliária, resultando no surgimento de subcentros ou novas centralidades para atender a algumas necessidades imediatas das populações mais próximas; 
- o deslocamento de parte significativa do comércio e dos serviços para os shopping centers em outros bairros;

v a saída do setor público (estadual e municipal - Poder Executivo e Poder Legislativo), como também a transferência da justiça estadual da área central da cidade para o bairro Edson Queiroz.

Além da população, a própria atividade econômica do Centro vem em decadência, como demonstrado pela queda da participação relativa da arrecadação de impostos e do número de empregos do bairro em relação ao município de Fortaleza.

Tomando novamente como referência a arrecadação de imposto sobre circulação de mercadorias e serviços (ICMS) (Ceará, 2004), uma análise histórica revela que, entre 1998 e 2002, a participação do Centro na economia estadual pouco oscilou, de $7 \%$ para $6 \%$; já a participação tanto do município de Fortaleza quanto da região metropolitana cresceram substancialmente, como reflexo do surgimento e/ou incremento de outras centralidades.

Quanto aos impostos de competência municipal, o Centro também se mostra com participação declinante em relação a outros bairros de Fortaleza, repetindo e confirmando o movimento decadente sugerido pela queda de participação na arrecadação de ICMS, revelada anteriormente. Entre 2002 e 2003, a participação do bairro na arrecadação municipal de imposto sobre serviços (ISS) caiu de $16,3 \%$ para $13,1 \%$, na de imposto sobre transmissão de bens intervivos (ITBI) de $5,2 \%$ para $3,2 \%$ e na de imposto sobre propriedade territorial urbana (IPTU) de 10,5\% para 9,9\% (Fortaleza - Sefin, 2002/2003).

Além disso, a contagem oficial de emprego do Sistema Nacional de Empregos, seção Ceará/Instituto do Desenvolvimento do Trabalho do Estado do Ceará (Sine/IDT), baseada na Relação Anual de Informações Sociais/Cadastro Geral de Empregados e Desempregados (Rais/Caged) (Sine/IDT, 2002/2003), demonstra que o estoque de empregos do Centro entre 2002 e 2003 esteve estagnado (redução de 0,33\%), enquanto os postos de trabalho do município apresentaram um ligeiro incremento de 0,67\%.

Diante de cenários de intensa competitividade entre o bairro e outros territórios, havia a necessidade de identificar, através de processo de planejamento, diretrizes estratégicas específicas que permitissem recuperar o Centro da cidade, resgatando o seu papel de referência urbana outrora ocupado. $\mathrm{O}$ bairro Centro de Fortaleza foi selecionado para a aplicação do modelo ECP territorial aproveitando a oportunidade de um trabalho para estudo de competitividade objeto de contratação por parte da Prefeitura de Fortaleza. A inclusão participativa de representantes da população do Centro também fez 
parte da aplicação da metodologia para facilitar o alcance de um conjunto de propostas de desenvolvimento factíveis de implementação. Os indicadores do modelo ECP territorial para o Centro foram construídos a partir dos dados obtidos e permitiram subsidiar a identificação de oportunidades de desenvolvimento para o bairro.

\section{A estrutura do ambiente competitivo em Fortaleza}

Mesmo sendo um dos bairros líderes de Fortaleza pela tradição e pelo tamanho de sua economia, o Centro enfrenta a concorrência, principalmente, de vários bairros vizinhos e de outras centralidades do município nos diversos setores econômicos em que está presente com relevância (quadro 4). Percebe-se que o Centro tem participação relevante, quando não lidera, em setores mais representativos da economia municipal, como o comércio varejista, a administração pública e os serviços profissionais, levando vantagem na competição com outros bairros importantes.

Quadro 4

Principais setores econômicos de atuação do Centro e principais competidores (2002)

\begin{tabular}{|c|c|c|c|c|}
\hline Setor & $\begin{array}{l}\text { Posição no } \\
\text { número de } \\
\text { empregos }\end{array}$ & $\begin{array}{l}\text { \% do bairro no } \\
\text { total de empregos } \\
\text { do setor no } \\
\text { município }\end{array}$ & $\begin{array}{l}\text { \% do setor } \\
\text { no total de } \\
\text { empregos do } \\
\text { município }\end{array}$ & $\begin{array}{c}\text { Principais bairros } \\
\text { competidores }\end{array}$ \\
\hline Construção civil & $1 \underline{a}$ & 12,7 & 5,6 & $\begin{array}{l}\text { Meireles, Aldeota, } \\
\text { Joaquim Távora }\end{array}$ \\
\hline $\begin{array}{l}\text { Indústria de } \\
\text { transformação }\end{array}$ & 3ạ & 5,9 & 16,0 & $\begin{array}{l}\text { Barra do Ceará, } \\
\text { Álvaro Weyne, } \\
\text { Messejana }\end{array}$ \\
\hline $\begin{array}{l}\text { Comércio } \\
\text { varejista }\end{array}$ & $1 \underline{a}$ & 31 & 17,3 & $\begin{array}{l}\text { Aldeota, Édson } \\
\text { Queiroz, Meireles, } \\
\text { Alagadiço São } \\
\text { Gerardo, Joaquim } \\
\text { Távora, Messejana }\end{array}$ \\
\hline $\begin{array}{l}\text { Comércio } \\
\text { atacadista }\end{array}$ & $1 \underline{a}$ & 23 & 3,0 & $\begin{array}{l}\text { Messejana, Aldeota, } \\
\text { Antônio Bezerra, } \\
\text { Joaquim Távora }\end{array}$ \\
\hline
\end{tabular}




\begin{tabular}{|c|c|c|c|c|}
\hline Setor & $\begin{array}{l}\text { Posição no } \\
\text { número de } \\
\text { empregos }\end{array}$ & $\begin{array}{l}\text { \% do bairro no } \\
\text { total de empregos } \\
\text { do setor no } \\
\text { município }\end{array}$ & $\begin{array}{l}\text { \% do setor } \\
\text { no total de } \\
\text { empregos do } \\
\text { município }\end{array}$ & $\begin{array}{l}\text { Principais bairros } \\
\text { competidores }\end{array}$ \\
\hline $\begin{array}{l}\text { Administração } \\
\text { pública }\end{array}$ & $2^{\mathrm{a}}$ & 30 & 12,9 & $\begin{array}{l}\text { Aldeota, Meireles, } \\
\text { Benfica, Cambeba }\end{array}$ \\
\hline Educação & $2 \mathrm{a}$ & 11,7 & 5,5 & $\begin{array}{l}\text { Benfica, Édson } \\
\text { Queiroz, Aldeota, } \\
\text { Parangaba, Meireles }\end{array}$ \\
\hline Saúde & $1 \underline{a}$ & 16,5 & 4,5 & $\begin{array}{l}\text { Rodolfo Teófilo, } \\
\text { Meireles, Aldeota, } \\
\text { Joaquim Távora, } \\
\text { Fátima, Papicu }\end{array}$ \\
\hline $\begin{array}{l}\text { Serviços } \\
\text { profissionais } \\
\text { (advocacia, } \\
\text { consultorias etc.) }\end{array}$ & $1 \underline{a}$ & 22,3 & 7,9 & $\begin{array}{l}\text { Aldeota, Joaquim } \\
\text { Távora, Dionísio } \\
\text { Torres, Meireles, } \\
\text { Montese }\end{array}$ \\
\hline $\begin{array}{l}\text { Alojamento e } \\
\text { alimentação }\end{array}$ & $1 \underline{a}$ & 22,0 & 4,5 & $\begin{array}{l}\text { Meireles, Aldeota, } \\
\text { Édson Queiroz, } \\
\text { Varjota }\end{array}$ \\
\hline $\begin{array}{l}\text { Atividades } \\
\text { associativas }\end{array}$ & $1 \underline{a}$ & 29,7 & 4,1 & $\begin{array}{l}\text { Aldeota, Jardim } \\
\text { América, Meireles, } \\
\text { Barra do Ceará }\end{array}$ \\
\hline $\begin{array}{l}\text { Atividades } \\
\text { imobiliárias }\end{array}$ & $4 \underline{a}$ & 12,4 & 3,8 & $\begin{array}{l}\text { Meireles, Joaquim } \\
\text { Távora, Aldeota, } \\
\text { Cocó, Dionísio Torres }\end{array}$ \\
\hline $\begin{array}{l}\text { Intermediação } \\
\text { financeira }\end{array}$ & $1 \underline{a}$ & 47,6 & 2,0 & $\begin{array}{l}\text { Aldeota, Joaquim } \\
\text { Távora, Meireles, } \\
\text { Alagadiço São } \\
\text { Gerardo }\end{array}$ \\
\hline
\end{tabular}

Fonte: Entrevistas com representantes do Centro; Ceará, 2004; Sine/IDT, 2002/2003.

Os bairros competidores podem ser agrupados conforme a definição de áreas de urbanização prioritárias do Plano Diretor de 1992 (em revisão) e denominadas centralidades, e suas regiões de influência imediata: Centro, Aldeota/Meireles, Seis Bocas, Messejana, Barra do Ceará/Carlito Pamplona, Antônio Bezerra e Parangaba/Montese. Foi acrescentada a área do Alagadiço São Gerardo, por ter significativa representatividade do comércio varejista (quadro 5). 


\section{Quadro 5 \\ Agrupamento das centralidades municipais e suas regiões de influência imediata}

\begin{tabular}{|c|c|}
\hline Grupo de centralidade & Principais bairros integrantes \\
\hline Vizinhos ao Centro & $\begin{array}{l}\text { Benfica, Joaquim Távora, Bairro de Fátima, Praia de Iracema, } \\
\text { Jacarecanga }\end{array}$ \\
\hline Centralidade Aldeota & $\begin{array}{l}\text { Aldeota, Meireles, Dionísio Torres, Papicu, Cocó, Varjota, } \\
\text { Mucuripe, Praia do Futuro }\end{array}$ \\
\hline Centralidade Parangaba & $\begin{array}{l}\text { Parangaba, Maraponga, Itaperi, Vila Peri, Jóquei Clube, } \\
\text { Bonsucesso }\end{array}$ \\
\hline Centralidade Messejana & $\begin{array}{l}\text { Messejana, Curió, Paupina, Lagoa Redonda, Guajaru, Coaçu, } \\
\text { Ancuri }\end{array}$ \\
\hline Centralidade Seis Bocas & $\begin{array}{l}\text { Édson Queiroz, Cambeba, Eng. Luciano Cavalcante, Édson } \\
\text { Queiroz, Cidade dos Funcionários }\end{array}$ \\
\hline Centralidade Montese & $\begin{array}{l}\text { Montese, São João do Tauape, Rodolfo Teófilo, Vila União, } \\
\text { Damas, Bom Futuro, Parreão, Demócrito Rocha, Bela Vista, } \\
\text { Couto Fernandes, Jardim América }\end{array}$ \\
\hline Centralidade Antônio Bezerra & $\begin{array}{l}\text { Antônio Bezerra, Quintino Cunha, Padre Andrade, Autran } \\
\text { Nunes, Dom Lustosa }\end{array}$ \\
\hline Centralidade Barra do Ceará & $\begin{array}{l}\text { Barra do Ceará, Álvaro Weyne, Carlito Pamplona, Cristo } \\
\text { Redentor, Vila Velha }\end{array}$ \\
\hline $\begin{array}{l}\text { Centralidade Alagadiço São } \\
\text { Gerardo (Av. Bezerra de Menezes) }\end{array}$ & $\begin{array}{l}\text { Alagadiço São Gerardo, Parquelândia, Monte Castelo, } \\
\text { Presidente Keneddy }\end{array}$ \\
\hline
\end{tabular}

Fonte: Entrevistas com representantes do Centro; Fortaleza, 2004.

Os setores econômicos mais importantes no Centro têm públicos distintos, prevalecendo um mais elitizado nas atividades localizadas a leste e um mais popular nas atividades localizadas a oeste. Os clientes do próprio bairro se destacam nas atividades de apoio como serviços profissionais, alimentação e indústrias gráficas e de confecções (quadro 6).

$$
\text { Quadro } 6
$$

Principais setores econômicos de atuação do Centro e principais mercados

\begin{tabular}{|ll|}
\hline Setor & \multicolumn{1}{c|}{ Principais mercados } \\
\hline Construção civil & Centro \\
Indústria de transformação & Centro, bairros da periferia e municípios da RMF \\
Comércio varejista & Bairros do Sudeste e bairros vizinhos do Leste de Fortaleza \\
Comércio atacadista & Bairros da periferia de Fortaleza e municípios da RMF \\
\hline
\end{tabular}




\begin{tabular}{|ll|}
\hline Setor & \multicolumn{1}{c|}{ Principais mercados } \\
\hline Administração pública & Todos os bairros de Fortaleza \\
Educação & Bairros do Sudeste e bairros vizinhos do Leste de Fortaleza \\
Saúde & Bairros da periferia de Fortaleza, municípios da RMF \\
Serviços profissionais & Centro e bairros vizinhos \\
(contabilidade, advocacia, & \\
consultorias etc.) & \\
Alojamento e alimentação & Centro e transeuntes de bairros/municípios atendidos por outros \\
& setores, turistas das regiões Sudeste e Norte do país a do exterior \\
Atividades associativas & Todos os bairros de Fortaleza \\
Atividade imobiliária & Centro \\
Intermediação financeira & Centro \\
\hline
\end{tabular}

Fonte: Entrevistas com representantes do Centro; Ceará, 2004; Sine/IDT, 2002/2003.

Apesar da decadência do bairro, é possível, complementarmente, destacar vantagens e desvantagens do Centro relativas a cada um dos principais setores econômicos existentes e outros setores com intenção declarada de desenvolvimento (quadro 7).

Quadro 7

Vantagens e desvantagens competitivas de setores econômicos no Centro

\begin{tabular}{|c|c|c|}
\hline Setor & Condições de oferta & Condições de demanda \\
\hline $\begin{array}{l}\text { Comércio } \\
\text { varejista }\end{array}$ & $\begin{array}{l}\text { - Acesso facilitado pelo transporte público } \\
\text { apenas para clientes populares } \\
\text { - Instituiç̃ões formadoras de pessoal com } \\
\text { elevado nível educacional } \\
\text { - Rede de setores gráficos, confecções, } \\
\text { serviços profissionais e alimentação } \\
\text { integrados ao varejo } \\
\text { - Potencial de maior integração ao } \\
\text { turismo }\end{array}$ & $\begin{array}{l}\text { - Público cativo para segmento de } \\
\text { clientes de menor poder aquisitivo } \\
\text { - Segmento de clientes de maior } \\
\text { poder aquisitivo em queda }\end{array}$ \\
\hline $\begin{array}{l}\text { Comércio } \\
\text { atacadista }\end{array}$ & $\begin{array}{l}\text { Logística desfavorável, tanto nas } \\
\text { condições de acesso quanto de carga e } \\
\text { descarga } \\
\text { - Tendência de concentração do setor em } \\
\text { maiores atacadistas } \\
\text { - Inexistência de setores integrados }\end{array}$ & $\begin{array}{l}\text { Clientes cada vez mais distantes, } \\
\text { buscando serviços baseados em } \\
\text { soluções tecnológicas (internet) }\end{array}$ \\
\hline
\end{tabular}

Continua 


\begin{tabular}{|c|c|c|}
\hline Setor & Condições de oferta & Condições de demanda \\
\hline Turismo & $\begin{array}{l}\text { - Rede de equipamentos e edificações } \\
\text { históricas e culturais } \\
\text { - Carência de infraestrutura específica } \\
\text { qualificada de apoio ao turista } \\
\text { - Potencial de integração com turismo } \\
\text { de lazer dos bairros vizinhos - Praia de } \\
\text { Iracema e Meireles }\end{array}$ & $\begin{array}{l}\text { - Ocupação sazonal, apenas } \\
\text { durante a semana, pelo segmento } \\
\text { de negócios } \\
\text { - Elevada demanda potencial } \\
\text { e exigente pelo segmento de } \\
\text { história/cultura }\end{array}$ \\
\hline $\begin{array}{l}\text { Administração } \\
\text { pública }\end{array}$ & $\begin{array}{l}\text { Edificações históricas disponíveis para } \\
\text { ocupação } \\
\text { - Acesso fácil à maior parte da população } \\
\text { - Setores de serviços profissionais, } \\
\text { entidades associativas e de } \\
\text { intermediação financeira integrados }\end{array}$ & $\begin{array}{l}\text { - Demanda reprimida pelos } \\
\text { serviços administrativos e pela } \\
\text { comunicação com os dirigentes } \\
\text { públicos }\end{array}$ \\
\hline $\begin{array}{l}\text { Construção } \\
\text { civil }\end{array}$ & $\begin{array}{l}\text { Recursos humanos abundantes de } \\
\text { qualificação adequada, vindos de outros } \\
\text { bairros por transporte coletivo } \\
\text { Prestadores de serviços especializados } \\
\text { em deslocamento para outros bairros }\end{array}$ & - Grande peso das obras públicas \\
\hline $\begin{array}{l}\text { Serviços de } \\
\text { saúde }\end{array}$ & $\begin{array}{l}\text { Acesso facilitado pelo transporte público } \\
\text { para clientes populares } \\
\text { - Predomínio dos serviços públicos } \\
\text { - Escolas de saúde distantes } \\
\text { - Existência de comércio varejista } \\
\text { especializado nas proximidades dos } \\
\text { equipamentos }\end{array}$ & $\begin{array}{l}\text { Público cativo para segmento } \\
\text { popular }\end{array}$ \\
\hline $\begin{array}{l}\text { Serviços de } \\
\text { educação }\end{array}$ & $\begin{array}{l}\text { - Acesso facilitado pelo transporte público } \\
\text { para clientes populares } \\
\text { - Boa infraestrutura de telecomunicações } \\
\text { - Avanço das instituições privadas } \\
\text { - Indústria gráfica competitiva, com } \\
\text { possibilidade de apoiar setor } \\
\text { educacional }\end{array}$ & $\begin{array}{l}\text { Público potencial para segmento } \\
\text { popular }\end{array}$ \\
\hline $\begin{array}{l}\text { Serviços } \\
\text { profissionais }\end{array}$ & $\begin{array}{l}\text { Boa infraestrutura para oferta de } \\
\text { serviços } \\
\text { Excelente integração com administração } \\
\text { pública e comércio varejista }\end{array}$ & $\begin{array}{l}\text { Dependente dos setores locais } \\
\text { competitivos } \\
\text { Demanda especializada em } \\
\text { deslocamento para outros bairros } \\
\text { (ex.: Aldeota/Meireles) }\end{array}$ \\
\hline
\end{tabular}




\begin{tabular}{|lll|}
\hline Setor & \multicolumn{1}{c|}{ Condições de oferta } & \multicolumn{1}{c|}{ Condições de demanda } \\
\hline Indústria de & Vecursos humanos abundantes de & - Clientes relevantes apenas para os \\
Transformação & qualificação adequada, vindos de outros & setores industriais integrados ao \\
& bairros por transporte público & comércio e aos serviços \\
& Infraestrutura física improvisada para & \\
& funcionamento de alguns setores & \\
& Comércio varejista competitivo fortalece \\
& setores integrados de confecções, \\
& alimentos e gráficas \\
\hline
\end{tabular}

Fonte: Pesquisa de campo (Sebrae, 2004).

\section{As condutas do Centro e de seus concorrentes}

A análise da conduta do Centro e de seus concorrentes em cada uma das bases territoriais pode revelar novos caminhos para o desenvolvimento do bairro no contexto do município de Fortaleza, ou ratificar outros já conhecidos. A comparação quantitativa da base urbana/demográfica, por exemplo, mostra que o Centro diferencia-se pela taxa negativa de crescimento populacional, mas encontra-se com elevados índices de cobertura da rede de abastecimento de água e de coleta de lixo, sendo que, no primeiro caso, está entre os bairros líderes e no segundo não há tanta diferença entre os bairros concorrentes (tabela 1).

Tabela 1

\section{Comparação da base urbana/demográfica do Centro e de seus principais concorrentes}

\begin{tabular}{|lccccc|}
\hline & $\begin{array}{c}\text { População } \\
\text { (mil } \\
\text { habitantes) } \\
\text { Território }\end{array}$ & $\begin{array}{c}\text { Densidade } \\
\text { demográfica } \\
\text { (hab./ha) }\end{array}$ & $\begin{array}{c}\text { Taxa média de } \\
\text { crescimento } \\
\text { populacional } \\
(\%)\end{array}$ & $\begin{array}{c}\text { Abastecimento } \\
\text { de água } \\
\text { (\% domicílios } \\
\text { rede geral) } \\
\text { 2000 }\end{array}$ & $\begin{array}{c}\text { Coleta } \\
\text { de lixo } \\
\text { (\% domićlios) } \\
\text { 2000 }\end{array}$ \\
\hline Fortaleza & 2.141 .402 & 63,9 & 2,15 & 87,22 & 95,20 \\
Centro & 24.775 & 45,4 & $-2,35$ & 91,10 & 99,06 \\
Aldeota & 38.636 & 98,1 & 1,71 & 93,31 & 99,89 \\
Meireles & 30.397 & 120,7 & 9,18 & 96,73 & 99,93 \\
Praia de Iracema & 3.150 & 90,0 & $-0,39$ & 90,53 & 98,04 \\
Eng. Luciano & 10.326 & 25,8 & 2,81 & 84,83 & 91,37 \\
Cavalcante & & & & & \\
Édson Queiroz & 20.291 & 12,7 & $-1,52$ & 84,93 & 93,80 \\
\hline
\end{tabular}




\begin{tabular}{|c|c|c|c|c|c|}
\hline Território & $\begin{array}{l}\text { População } \\
\text { (mil } \\
\text { habitantes) } \\
2000\end{array}$ & $\begin{array}{c}\text { Densidade } \\
\text { demográfica } \\
\text { (hab./ha) } \\
2000\end{array}$ & $\begin{array}{c}\text { Taxa média de } \\
\text { crescimento } \\
\text { populacional } \\
(\%) \\
1991-2000\end{array}$ & $\begin{array}{l}\text { Abastecimento } \\
\text { de água } \\
\text { (\% domicílios } \\
\text { rede geral) } \\
2000\end{array}$ & $\begin{array}{c}\text { Coleta } \\
\text { de lixo } \\
\text { (\% domicílios) } \\
2000\end{array}$ \\
\hline $\begin{array}{l}\text { Parque } \\
\text { Manibura }\end{array}$ & 6.833 & 37,6 & 6,07 & 85,18 & 98,73 \\
\hline Cambeba & 5.428 & 21,6 & 2,54 & 81,95 & 95,19 \\
\hline Messejana & 38.374 & 57,3 & 0,63 & 93,96 & 98,82 \\
\hline Antônio Bezerra & 24.698 & 105,6 & $-0,21$ & 87,09 & 97,96 \\
\hline $\begin{array}{l}\text { Alagadiço São } \\
\text { Gerardo }\end{array}$ & 13.117 & 91,7 & 0,68 & 89,63 & 99,73 \\
\hline Benfica & 12.932 & 90,4 & $-1,16$ & 96,08 & 99,29 \\
\hline $\begin{array}{l}\text { Bairro de Fátima } \\
\text { (Távora) }\end{array}$ & 23.070 & 71,5 & $-0,76$ & 93,34 & 96,16 \\
\hline Joaquim Távora & 23.051 & 115,6 & $-0,93$ & 90,46 & 99,80 \\
\hline Parangaba & 28.045 & 72,0 & $-0,07$ & 81,83 & 97,78 \\
\hline Montese & 26.062 & 136,7 & 0,51 & 89,09 & 99,48 \\
\hline Barra do Ceará & 69.317 & 179,8 & 3,49 & 81,46 & 96,52 \\
\hline $\begin{array}{l}\text { Carlito } \\
\text { Pamplona }\end{array}$ & 24.383 & 192,3 & 1,94 & 86,09 & 99,38 \\
\hline
\end{tabular}

Fonte: IBGE, 2001; Fortaleza/Sepla, 2003; Fortaleza, 2003.

Quanto à base econômica, verifica-se que o Centro compete por meio de um setor terciário forte assim como as principais centralidades, com exceção da Barra do Ceará e do Antônio Bezerra, que se diferenciam por possuir setor industrial mais representativo (tabela 2). A participação de $90 \%$ do setor terciário no Centro, bem superior à média municipal de $56 \%$, ratifica a sua vocação histórica.

Tabela 2

Comparação da base econômica do Centro e de seus principais concorrentes (2002)

\begin{tabular}{|lccc|}
\hline Território & $\begin{array}{c}\text { \% dos empregos no } \\
\text { setor primário }\end{array}$ & $\begin{array}{c}\text { \% dos empregos no } \\
\text { setor secundário }\end{array}$ & $\begin{array}{c}\text { \% dos empregos no } \\
\text { setor terciário }\end{array}$ \\
\hline Fortaleza & 1 & 43 & 56 \\
Centro & 1 & 9 & 90 \\
Aldeota & 0 & 13 & 87 \\
Meireles & 0 & 8 & 92 \\
\hline
\end{tabular}




\begin{tabular}{|lccc|}
\hline Território & $\begin{array}{c}\text { \% dos empregos no } \\
\text { setor primário }\end{array}$ & $\begin{array}{c}\text { \% dos empregos no } \\
\text { setor secundário }\end{array}$ & $\begin{array}{c}\text { \% dos empregos no } \\
\text { setor terciário }\end{array}$ \\
\hline Praia de Iracema & 0 & 16 & 84 \\
Eng. Luciano & ND & ND & ND \\
Cavalcante & 0 & 21 & 79 \\
Édson Queiroz & ND & ND & ND \\
Parque Manibura & 0 & 40 & 60 \\
Cambeba & 7 & 31 & 62 \\
Messejana & 24 & 28 & 48 \\
Antônio Bezerra & 14 & 19 & 67 \\
Alagadiço São & 0 & & 95 \\
Gerardo & 0 & 5 & 90 \\
Benfica & 0 & 10 & 84 \\
Bairro de Fátima & 0 & 16 & 69 \\
Joaquim Távora & 0 & 31 & 83 \\
Parangaba & 0 & 17 & 24 \\
Montese & $N D$ & ND & ND \\
Barra do Ceará & & & \\
Carlito Pamplona & 004 & 16 & \\
\hline
\end{tabular}

Fonte: Sine/IDT, 2002/2003; Ceará, 2004.

ND = Não disponível. Os bairros Carlito Pamplona, Eng. Luciano Cavalcante e Parque Manibura não dispõem de estatísticas individualizadas de empregos

No tocante à base social, o Centro ocupa uma posição de liderança em leitos/habitante, considerando a oferta do Sistema Único de Saúde (SUS) e próxima dos líderes em termos de cobertura para atendimento da educação pública (tabela 3). Alguns bairros mais nobres, como Aldeota, Meireles, Benfica, Joaquim Távora e Praia de Iracema, que aparecem com poucas salas de aula públicas, devem ter suas ofertas complementadas pelo setor educacional privado.

Tabela 3

Comparação da base social do Centro e de seus principais concorrentes (2003)

\begin{tabular}{|lcccc|}
\hline Território & $\begin{array}{c}\text { Salas de aula*/ } \\
\text { mil habitantes }\end{array}$ & $\begin{array}{c}\text { Professores* } \\
100 \text { alunos }\end{array}$ & $\begin{array}{c}\text { Leitos**/100 } \\
\text { habitantes }\end{array}$ & $\begin{array}{c}\text { Consultas } \\
\text { médicas**/habitante }\end{array}$ \\
\hline Fortaleza & 1,78 & 1,67 & 0,34 & 0,42 \\
Centro & 1,43 & 5,79 & 6,22 & 0,40 \\
Aldeota & 0,30 & 4,09 & 0,66 & 0,05 \\
\hline
\end{tabular}




\begin{tabular}{|c|c|c|c|c|}
\hline Território & $\begin{array}{c}\text { Salas de aula*/ } \\
\text { mil habitantes }\end{array}$ & $\begin{array}{c}\text { Professores*/ } \\
100 \text { alunos } \\
\end{array}$ & $\begin{array}{l}\text { Leitos**/100 } \\
\text { habitantes }\end{array}$ & $\begin{array}{c}\text { Consultas } \\
\text { médicas } * * * / \text { habitante }\end{array}$ \\
\hline Meireles & 0,00 & 0,00 & 0,22 & 0,03 \\
\hline Praia de Iracema & 0,00 & 0,00 & 0,00 & 0,31 \\
\hline $\begin{array}{l}\text { Eng. Luciano } \\
\text { Cavalcante }\end{array}$ & 2,67 & 5,10 & 0,00 & 0,50 \\
\hline Édson Queiroz & 2,06 & 2,92 & 0,00 & 0,73 \\
\hline Parque Manibura & 0,00 & 0,00 & 0,53 & 0,05 \\
\hline Cambeba & 0,00 & 0,00 & 0,00 & 0,06 \\
\hline Messejana & 3,89 & 3,09 & 2,54 & 0,35 \\
\hline Antônio Bezerra & 2,57 & 3,47 & 0,21 & 1,34 \\
\hline $\begin{array}{l}\text { Alagadiço São } \\
\text { Gerardo }\end{array}$ & 2,61 & 6,32 & 2,32 & 0,27 \\
\hline Benfica & 0,00 & 0,00 & 2,48 & 0,60 \\
\hline Bairro de Fátima & 0,89 & 3,18 & 0,00 & 0,42 \\
\hline Joaquim Távora & 0,00 & 0,00 & 0,09 & 0,30 \\
\hline Parangaba & 0,60 & 3,71 & 1,91 & 1,09 \\
\hline Montese & 0,15 & 4,46 & 0,49 & 0,66 \\
\hline Barra do Ceará & 1,29 & 2,09 & 0,19 & 0,68 \\
\hline Carlito Pamplona & 0,93 & 2,59 & 0,00 & 0,08 \\
\hline
\end{tabular}

Fonte: IBGE, 2001; Ceará, 2003; Fortaleza/Sedas, 2003; Ipece, 2004.

* Apenas escolas públicas até 2o grau. Professores e salas de aula do início de 2004.

** Leitos clínicos, cirúrgicos, de intercorrência, complementares e de desintoxicação do SUS e população estimada para 2003.

*** Consultas através do SUS apenas e população estimada para 2003.

Por sua capacidade econômica, o Centro, se considerado uma entidade pública em separado, ostentaria uma situação financeira favorável, possivelmente com superávit orçamentário, sugerindo uma base institucional do poder público potencialmente forte quando comparada à de seus maiores concorrentes. Da mesma forma, quanto à organização do poder privado, o Centro, em termos quantitativos, encontra-se em situação favorável, com ativa participação popular da sociedade civil, quando representada por entidades associativas (tabela 4). 
Tabela 4

Comparação da base institucional do Centro e de seus principais concorrentes (2000)

\begin{tabular}{|lcc|}
\hline Território & $\begin{array}{c}\text { № de entidades associativas/ } \\
\text { mil habitantes }\end{array}$ & $\begin{array}{c}\text { Receita própria bairro/ } \\
\text { município (\%)* }\end{array}$ \\
\hline Fortaleza & 1,11 & 100 \\
Centro & 18,24 & 13 \\
Aldeota & 3,44 & 14 \\
Meireles & 4,01 & 10 \\
Praia de Iracema & 4,44 & 1 \\
Eng. Luciano Cavalcante & $N D$ & ND \\
Édson Queiroz & 1,28 & 2 \\
Parque Manibura & $N D$ & 1 \\
Cambeba & 0,74 & 0 \\
Messejana & 1,98 & 1 \\
Antônio Bezerra & 1,46 & 0 \\
Alagadiço São Gerardo & 2,59 & 1 \\
Benfica & 4,10 & 1 \\
Bairro de Fátima & 1,86 & 4 \\
Joaquim Távora & 3,17 & 2 \\
Parangaba & 2,18 & 1 \\
Montese & 0,88 & 0 \\
Barra do Ceará & 1,34 & 1 \\
Carlito Pamplona & $N D$ & 0 \\
\hline
\end{tabular}

Fonte: Fortaleza/Sefin, 2002/2003; IBGE, 2001; Sine/IDT, 2002/2003.

* Inclui apenas ISS, IPTU e ITBI, totalizando R\$ 178 milhões.

ND = Não disponível. Os bairros Carlito Pamplona, Eng. Luciano Cavalcante e Parque Manibura não dispõem de estatísticas individualizadas de estabelecimentos empregadores.

A avaliação qualitativa da conduta do Centro em relação aos setores específicos, sob os aspectos público e privado, revela situações de desobediência das regras pelas empresas, fruto da inadequação das regras em relação aos setores econômicos ou de práticas competitivas nocivas (quadro 8). 
Quadro 8

\section{Condutas específicas por setor econômico no Centro}

\begin{tabular}{|c|c|}
\hline Setor & Conduta setorial \\
\hline Comércio varejista & $\begin{array}{l}\text { Forte consciência de associativismo } \\
\text { - Desobediência ao Código de Posturas } \\
\text { - Informalidade de algumas categorias }\end{array}$ \\
\hline Comércio atacadista & $\begin{array}{l}\text { - Leis municipais restritivas } \\
\text { Prática de flexibilidade fiscal degenerativa } \\
\text { - Limitada atuação conjunta do setor }\end{array}$ \\
\hline Turismo & $\begin{array}{l}\text { - Baixa sensibilidade popular para preservação do patrimônio histórico } \\
\text { - Dependência de recursos públicos para conservação do patrimônio }\end{array}$ \\
\hline Administração pública & $\begin{array}{l}\text { - Limitado interesse ou desconhecimento da importância da simbologia } \\
\text { central por parte dos dirigentes públicos }\end{array}$ \\
\hline Construção civil & - Existência de restrições pelo Código de Obras \\
\hline Serviços de saúde & - Dependente de investimentos públicos, normalmente limitados \\
\hline Serviços de educação & - Ausência de regras específicas de localização \\
\hline Serviços profissionais & - Limitada experiência associativa \\
\hline $\begin{array}{l}\text { Indústria de } \\
\text { transformação }\end{array}$ & - Informalidade de algumas categorias \\
\hline
\end{tabular}

Fonte: Pesquisa de campo; Fortaleza, 2002; Fortaleza, 1998.

\section{A análise comparativa de performance dos bairros de Fortaleza}

Após a comparação das ferramentas componentes das bases locais e da análise de competitividade do Centro, parte-se então para comparação entre o desempenho do Centro e de seus principais concorrentes, que poderá ser diferenciada pela atuação distinta de cada bairro sobre as ferramentas de conduta.

Como parâmetros para aferir o desenvolvimento econômico e social dos bairros de Fortaleza, foram escolhidos três indicadores, que trazem certa semelhança com aqueles utilizados na formação do IDH, com a vantagem de serem acompanhados e disponíveis por bairros de Fortaleza. Esses indicadores, listados a seguir, são integrantes do índice de desenvolvimento humano municipal-Bairro (IDHM-B), calculado pela metodologia específica, desenvolvida no Plano Estratégico de Fortaleza (Fortaleza/Sepla, 2002):

v taxa de analfabetismo - pessoas de 15 anos ou mais. Este índice não sofreu qualquer modificação, sendo utilizados os dados do censo 2000 (IBGE, 
2001), disponível no nível de bairros. Os valores limites utilizados foram: pior valor $-100 \%$, melhor valor $-0 \%$;

v número médio de anos de estudo dos chefes de família - esse indicador foi utilizado, em lugar do número médio de anos de estudo da população de 25 anos ou mais, previsto na metodologia original, devido à indisponibilidade dos dados do IBGE por ocasião do estudo. Os valores limites utilizados foram: pior valor -0 ano, melhor valor -16 anos;

v rendimento médio do chefe de família em salários mínimos - a metodologia original do IDH-M do Instituto de Pesquisa Econômica Aplicada (Ipea) utiliza a renda per capita média. Para este índice, foram utilizados dados do IBGE onde os valores limites foram: pior valor $-0,05$ salário mínimo; melhor valor - 30 salários mínimos.

Não foi utilizado qualquer indicador que representasse o grau de saúde da população, como existente no IDH original, pela indisponibilidade de dados para comparação, como também para o estado da segurança ou do meio ambiente.

Assim, com o IDHM-B, percebe-se que o bairro ocupa uma posição intermediária em termos de desenvolvimento econômico perante seus concorrentes. Quanto ao desenvolvimento social, o Centro ocupa uma posição bem favorável, principalmente pelo efeito do elevado nível educacional da população que compensa parcialmente o menor rendimento (tabela 5). No IDHM-B geral, o Centro está mais distante de Meireles e Aldeota e próximo a Alagadiço São Gerardo, Praia de Iracema, Benfica e Cambeba. E acima da média municipal.

Tabela 5

Comparação de desempenho do Centro e concorrentes conforme indicadores socioeconômicos (2000)

\begin{tabular}{|lcccc|}
\hline Bairro & $\begin{array}{c}\text { IDHM-B anos } \\
\text { estudo }\end{array}$ & $\begin{array}{c}\text { IDHM-B pop. } \\
\text { analfabeta }\end{array}$ & $\begin{array}{c}\text { IDHM-B } \\
\text { rendimento }\end{array}$ & $\begin{array}{c}\text { IDHM-B } \\
\text { geral }\end{array}$ \\
\hline Fortaleza & 0,450 & 0,888 & 0,186 & 0,508 \\
Centro & 0,636 & 0,959 & 0,287 & 0,627 \\
Aldeota & 0,789 & 0,965 & 0,736 & 0,830 \\
Meireles & 0,824 & 0,977 & 0,947 & 0,916 \\
Praia de Iracema & 0,677 & 0,964 & 0,410 & 0,684 \\
Eng. Luciano Cavalcante & 0,536 & 0,917 & 0,323 & 0,592 \\
Édson Queiroz & 0,438 & 0,854 & 0,207 & 0,500 \\
\hline
\end{tabular}




\begin{tabular}{|lcccc|}
\hline Bairro & $\begin{array}{c}\text { IDHM-B anos } \\
\text { estudo }\end{array}$ & $\begin{array}{c}\text { IDHM-B pop. } \\
\text { analfabeta }\end{array}$ & $\begin{array}{c}\text { IDHM-B } \\
\text { rendimento }\end{array}$ & $\begin{array}{c}\text { IDHM-B } \\
\text { geral }\end{array}$ \\
\hline Parque Manibura & 0,359 & 0,837 & 0,090 & 0,429 \\
Cambeba & 0,601 & 0,917 & 0,369 & 0,629 \\
Messejana & 0,442 & 0,877 & 0,124 & 0,481 \\
Antônio Bezerra & 0,447 & 0,911 & 0,132 & 0,497 \\
Alagadiço São Gerardo & 0,716 & 0,974 & 0,345 & 0,678 \\
Benfica & 0,708 & 0,971 & 0,312 & 0,664 \\
Bairro de Fátima & 0,738 & 0,965 & 0,444 & 0,716 \\
Joaquim Távora & 0,659 & 0,962 & 0,346 & 0,656 \\
Parangaba & 0,531 & 0,932 & 0,185 & 0,549 \\
Montese & 0,533 & 0,932 & 0,184 & 0,550 \\
Barra do Ceará & 0,356 & 0,860 & 0,080 & 0,432 \\
Carlito Pamplona & 0,437 & 0,904 & 0,109 & 0,483 \\
\hline
\end{tabular}

Fonte: Fortaleza/Sepla, 2002.

A partir do diagnóstico local e da comparação com os bairros concorrentes, podem ser destacados alguns pontos fortes e fracos do Centro de Fortaleza (quadro 9).

Quadro 9

Pontos fortes e pontos fracos do Centro

\begin{tabular}{|c|c|c|}
\hline $\begin{array}{l}\text { Base do sistema } \\
\text { territorial }\end{array}$ & Pontos fortes & Pontos fracos \\
\hline Natural & $\begin{array}{l}\text { - Localização geográfica } \\
\text { - Relevo relativamente plano }\end{array}$ & $\begin{array}{l}\text { - Acesso limitado ao litoral } \\
\text { - Recursos hídricos degradados e } \\
\text { poluídos }\end{array}$ \\
\hline Urbana/demográfica & $\begin{array}{l}\text { Patrimônio histórico e cultural } \\
\text { - Infraestrutura de utilidades }\end{array}$ & $\begin{array}{l}\text { - Interligação com bairros mais } \\
\text { afluentes } \\
\text { - Serviços de limpeza }\end{array}$ \\
\hline Institucional & $\begin{array}{l}\text { Convergência de } \\
\text { manifestações políticas e } \\
\text { culturais } \\
\text { - Organização de entidades de } \\
\text { classe } \\
\text { - Investimento regular do setor } \\
\text { público } \\
\text { - Arrecadação própria de } \\
\text { tributos }\end{array}$ & $\begin{array}{l}\text { Obediência à legislação de uso e } \\
\text { ocupação do solo e ao Código de } \\
\text { Posturas }\end{array}$ \\
\hline
\end{tabular}




\begin{tabular}{|c|c|c|}
\hline $\begin{array}{l}\text { Base do sistema } \\
\text { territorial }\end{array}$ & Pontos fortes & Pontos fracos \\
\hline Social & - Equipamentos de saúde & - Segurança \\
\hline Econômica & $\begin{array}{l}\text { Setor terciário (comércio } \\
\text { varejista e serviços correlatos) } \\
\text { vscolaridade de seus } \\
\text { habitantes }\end{array}$ & $\begin{array}{l}\text { Informalidade e qualificação dos } \\
\text { empreendedores } \\
\text { - Comércio atacadista e turismo } \\
\text { histórico-cultural }\end{array}$ \\
\hline
\end{tabular}

Fonte: Pesquisa de campo; Fortaleza/Sepla, 2002; Fortaleza/Sefin, 2002/2003.

\section{Relação entre conduta e performance em Fortaleza}

Ressalte-se que, devido à limitação de dados, os indicadores de desempenho se referem a períodos anteriores a alguns dos indicadores de conduta dos bairros. Assim, qualquer relação de causa e efeito só pode ser inferida se assumirmos que as variações relativas dos indicadores de conduta dos bairros foram pequenas no período de tempo considerado, o que é razoável, já que houve continuidade administrativa em Fortaleza nesse intervalo e que as mudanças no setor público costumam ser mais lentas. Há um fator inercial nas funções públicas. De qualquer forma, por esse motivo, é preciso ratificar as conclusões do caso quando da disponibilidade de dados mais recentes, mas a dificuldade de obtenção de dados de bairro não deve interferir no mérito do modelo. A disponibilidade de informações de bairro certamente poderia enriquecer este artigo.

Nessas condições, avaliando o desempenho do Centro e seus concorrentes diante de um ambiente competitivo municipal, foram identificados alguns padrões de conduta para bairros bem-sucedidos social e economicamente no município de Fortaleza:

v os bairros com melhor condição de desenvolvimento econômico têm forte participação do setor terciário em suas economias (a participação dos empregos do setor terciário correlaciona-se positivamente com IDHM-B geral). Aparentemente, porque esses setores apresentam maior competitividade no território municipal visto que o município de Fortaleza é um polo regional de serviços;

v os bairros com maior cobertura de serviços sociais não necessariamente apresentam melhores resultados sociais, sugerindo que a qualidade dos serviços também é forte ferramenta de desenvolvimento social. Há também a possibilidade de não ter havido tempo suficiente para influenciar os resultados. 


\section{Os cenários do ambiente competitivo diante dos choques}

A construção de cenários que possam vir a alterar a posição relativa do Centro nos setores da economia em que hoje o bairro se apresenta competitivo ou potencialmente competitivo é imperativa. Devem ser avaliados eventos de amplo espectro, fora do controle dos gestores locais, porém com efeito local diferenciado.

Uma análise de possíveis eventos externos ao bairro aponta para algumas ameaças, principalmente ao principal setor competitivo do Centro, o comércio varejista, provocadas por grandes projetos públicos, mudança de hábito de consumidores, inovações tecnológicas, entrada de novos competidores e alterações tributárias. Há também oportunidades para comércio e serviços voltados para classes populares e turistas, que devem ser objeto de ações presentes (quadro 10).

Quadro 10

Possíveis choques externos, implicações e reações - Centro

\begin{tabular}{|c|c|c|c|}
\hline Classe & Possíveis eventos & Implicações & Possíveis reações \\
\hline \multirow[t]{3}{*}{$\begin{array}{l}\text { Projetos } \\
\text { municipais, } \\
\text { estaduais e } \\
\text { nacionais }\end{array}$} & $\begin{array}{l}\text { Implantação do Centro } \\
\text { Multifuncional de Feiras } \\
\text { e Eventos }\end{array}$ & $\begin{array}{l}\text { Preferência de novas } \\
\text { empresas do aglomerado de } \\
\text { turismo pelo Centro e bairros } \\
\text { vizinhos }\end{array}$ & $\begin{array}{l}\text { Fortalecer setor de } \\
\text { serviços, infraestrutura } \\
\text { urbana e mão de obra } \\
\text { para atrair empresas do } \\
\text { setor turístico para o } \\
\text { Centro }\end{array}$ \\
\hline & $\begin{array}{l}\text { Construção das linhas de } \\
\text { metrô Centro-Caucaia e } \\
\text { Centro-Aldeota }\end{array}$ & $\begin{array}{l}\text { Aumento do fluxo de } \\
\text { pessoas pelo Centro, } \\
\text { possibilitando uma maior } \\
\text { utilização da ferrovia } \\
\text { para comercialização dos } \\
\text { produtos/serviços do bairro }\end{array}$ & $\begin{array}{l}\text { Providenciar ordenação } \\
\text { da área de influência } \\
\text { do metrô, otimizando } \\
\text { usos e retornos dos } \\
\text { investimentos, reforçando } \\
\text { potenciais locais }\end{array}$ \\
\hline & $\begin{array}{l}\text { Implantação do Projeto } \\
\text { BID/FOR }\end{array}$ & $\begin{array}{l}\text { Possível alteração dos canais } \\
\text { de fluxos de pessoas ou } \\
\text { mesmo redução do fluxo de } \\
\text { pessoas pelo Centro, com o } \\
\text { intuito de melhorar o sistema } \\
\text { de transportes municipal }\end{array}$ & $\begin{array}{l}\text { Identificar, ordenar } \\
\text { e preparar os novos } \\
\text { canais de fluxos de } \\
\text { pessoas para integrá-los } \\
\text { à economia local }\end{array}$ \\
\hline $\begin{array}{l}\text { Hábitos dos } \\
\text { consumidores }\end{array}$ & $\begin{array}{l}\text { Continuada sensação de } \\
\text { insegurança pessoal nos } \\
\text { logradouros públicos }\end{array}$ & $\begin{array}{l}\text { Popularização e crescente } \\
\text { informalização das atividades } \\
\text { econômicas do Centro }\end{array}$ & $\begin{array}{l}\text { Renovação de áreas } \\
\text { para o comércio voltado } \\
\text { para classes de maior } \\
\text { poder aquisitivo }\end{array}$ \\
\hline
\end{tabular}




\begin{tabular}{|c|c|c|c|}
\hline Classe & Possíveis eventos & Implicações & Possíveis reações \\
\hline Tecnologia & $\begin{array}{l}\text { Crescente facilidade } \\
\text { de acesso e troca de } \\
\text { informações (internet) }\end{array}$ & $\begin{array}{l}\text { Redução da necessidade } \\
\text { de deslocamento para } \\
\text { recebimento de serviços } \\
\text { (educação, saúde, comércio) }\end{array}$ & $\begin{array}{l}\text { Instalar infraestrutura } \\
\text { de comunicações } \\
\text { moderna que dê } \\
\text { suporte ao rápido } \\
\text { acesso à informação, à } \\
\text { prestação/recebimento } \\
\text { de serviços virtuais e ao } \\
\text { comércio eletrônico }\end{array}$ \\
\hline Legislação & $\begin{array}{l}\text { Concessão de incentivos } \\
\text { fiscais de ISS, IPTU entre } \\
\text { outros, por municípios } \\
\text { da RMF }\end{array}$ & $\begin{array}{l}\text { Redução da atratividade } \\
\text { do Centro para setores } \\
\text { beneficiados se comparado } \\
\text { com municípios da RMF }\end{array}$ & $\begin{array}{l}\text { Atrair empresas que } \\
\text { independam de } \\
\text { incentivos fiscais para } \\
\text { sobreviver }\end{array}$ \\
\hline \multirow[t]{2}{*}{$\begin{array}{l}\text { Novos } \\
\text { competidores }\end{array}$} & $\begin{array}{l}\text { Surgimento/ } \\
\text { consolidação de novas } \\
\text { centralidades municipais } \\
\text { e metropolitanas }\end{array}$ & $\begin{array}{l}\text { Redução da competitividade } \\
\text { do Centro em setores de } \\
\text { serviços explorados por estas } \\
\text { centralidades }\end{array}$ & $\begin{array}{l}\text { Identificar nichos de } \\
\text { mercado para produtos/ } \\
\text { serviços adequados às } \\
\text { condições do bairro }\end{array}$ \\
\hline & & & $\begin{array}{l}\text { Conquistar a maior } \\
\text { participação de mercado } \\
\text { possível, modernizar } \\
\text { setores atuais e criar } \\
\text { maneiras de fidelizar } \\
\text { clientes e atuar em } \\
\text { nichos enquanto novas } \\
\text { centralidades estiverem } \\
\text { fora do mercado }\end{array}$ \\
\hline
\end{tabular}

Fonte: Entrevistas com representantes das entidades de classe do Centro.

Com base nesses choques externos, cujas ocorrências em separado podem ser vistas como formadoras de cenários independentes, e na análise competitiva do Centro diante dos demais bairros do município, revelada pelos demais elementos do modelo ECP territorial, é possível promover uma maior discussão com os diversos grupos de interesse do Centro e construir uma proposta de desenvolvimento para o bairro que seja consistente e sustentável.

\section{A compreensão da estratégia municipal}

Complementando o processo de avaliação competitiva e de desenvolvimento de estratégias para o Centro, foram realizadas consultas a planos de desen- 
volvimento e similares realizados para outros bairros e para o município, em que se explicitem condições de contorno a serem observadas ou desafiadas pelo Centro.

O Plano Estratégico de Fortaleza (Fortaleza/Sepla, 2002) optou por não apontar setores em que o município deveria buscar maior competitividade, indicando apenas caminhos para melhoria do ambiente geral de negócios, o que, por um lado, dá flexibilidade ao Centro para definir seu próprio caminho e, por outro, o deixa sem âncora setorial para fixar suas proposições.

Outro estudo local de desenvolvimento, o Estudo Socioeconômico, Urbanístico e Ambiental das Sedes de Parangaba e Messejana (Fortaleza/Sepla, 2003), sugere normatização do comércio varejista e atacadista na Parangaba e fortalecimento do turismo e do comércio varejista em Messejana, reiterando a disposição competidora desses bairros em relação ao Centro.

\section{Diretrizes gerais para o desenvolvimento do Centro de Fortaleza}

Apesar da vitalidade aparente do bairro e, para alguns, contraditória, a evolução temporal de indicadores de vitalidade como arrecadação de impostos e números de empregos revela que o Centro está, de fato, em declínio econômico em relação aos demais bairros de Fortaleza, assim como se tinha conhecimento relativamente à população local.

Mantidas as atuais práticas das atividades econômicas e a ineficácia de instrumentos reguladores e normativos para ocupação, uso e preservação do espaço, pode-se esperar um incremento da degradação urbana e antever um crescente esvaziamento da população local, apesar da excelente configuração das infraestruturas de suporte humano, apenas com restrições de mobilidade aos automóveis.

A análise pelo modelo ECP territorial sugere que o setor da economia com maiores condições de competitividade no Centro em relação aos demais bairros é o comércio varejista com todos os setores econômicos a ele integrados. Mostra também que há um potencial para desenvolvimento do turismo histórico-cultural e de recuperação da presença da administração pública. O setor de comércio atacadista parece não encontrar competitividade local e tenderia a definhar. Assim, são apresentadas diretrizes, fundamentadas nos princípios de competitividade do modelo ECP territorial, que devem promover a reabilitação do Centro de Fortaleza. Essas diretrizes são baseadas na ordenação do comércio varejista, na remoção do comércio atacadista, na descoberta do turismo histórico-cultural, no retorno da administração pública e no re- 
forço aos setores correlatos de serviços e indústrias. Complementarmente, há a necessidade de ações de estruturação urbana para resgatar o Centro como um território democrático e de todos os cidadãos, independentemente de sua classe de renda, e que merecem maior detalhamento em outros estudos.

\section{Conclusões}

Este artigo toma por base o modelo ECP para ampliar sua aplicação a territórios, mais especificamente a bairros, gerando o modelo ECP territorial, que permite inferir a performance dos territórios em busca de seu desenvolvimento a partir da análise das condutas de todos os territórios competidores no ambiente em que se inserem.

Em Fortaleza, onde o modelo ECP territorial foi aplicado, há evidências claras de que é chegado o momento onde todos os esforços devem ser feitos para que o Centro continue a ser o foco da comunidade da capital, e permaneça sendo o core econômico da região urbanizada, representante principal da imagem urbana da cidade.

A aplicação do modelo ECP territorial permitiu identificar estratégias setoriais seletivas consistentes de desenvolvimento para o Centro e demonstram que a oportunidade de revitalização é real, e seu não aproveitamento poderá acarretar desequilíbrios espaciais na ocupação do território municipal com entraves ao desenvolvimento do município como um todo. Adicionalmente, foi criada uma base de informações sobre a competitividade dos bairros de Fortaleza que permite um planejamento territorial integrado para o município, inclusive com a incorporação da estratégia de desenvolvimento do Centro.

Pela importância que intervenções de caráter estruturante têm demonstrado em projetos de requalificação de zonas centrais, poder-se-ia dizer que as diretrizes apresentadas dizem respeito aos pontos focais sobre os quais devem incidir soluções urbanísticas capazes de atrair habitantes e visitantes de todas as classes de renda, melhorar a qualidade do espaço público, alcançar a eficiência da mobilidade urbana e promover o realce e a proteção do patrimônio histórico do Centro de Fortaleza. A partir da aplicação da estratégia orientadora que visa conduzir as gestões de desenvolvimento local do Centro, no tocante ao conteúdo dos procedimentos e produtos, as ações básicas de caráter operacional para implementação das diretrizes apontadas deverão ser discriminadas, desdobradas e articuladas em uma agenda local.

Por fim, este artigo expande a análise estratégica para territórios de forma metodologicamente consistente e passível de utilização prática em con- 
dições locais. Ao mesmo tempo, estabelece um roteiro para processos de revitalização de centros urbanos, aplicando-o ao caso latente e emblemático do Centro de Fortaleza.

Como sugestão para próximos trabalhos, propõe-se detalhar a generalização do modelo ECP territorial para aplicações em qualquer porte de território, pois, embora desenvolvido para ser aplicado genericamente, o modelo foi aplicado a um bairro, e pode ser transportado para escalas maiores, como municípios, regiões de municípios, estados e assim sucessivamente.

\section{Referências}

ABREU, M. C. S.; FIGUEIRÊDO JR., H. S.; VARVAKIS, G. As pressões ambientais da estrutura da indústria. Revista de Administração de Empresas - RAE, v. 3, n. 2, jul./dez. 2004.

CEARÁ (SEFAZ). Sistema de arrecadação estadual. Fortaleza, 2004.

(SESA). Estatísticas de saúde. Fortaleza, 2003.

CHADWICK, G. F. Una vision sistemica del planeamiento. Barcelona: Gustavo Gili, 1973.

COPELAND, T., KOLLER, T., MURRIN, J. Valuation: measuring and managing the value of companies. New York: McKinsey and Company; J. Wiley \& Sons, 1994.

FORTALEZA. Lei n. 8.234, de 29 de dezembro de 1998. Diário Oficial do Município. Fortaleza, 30 dez. 1998.

. Decreto n. 11.252, de 10 de setembro de 2002. Diário Oficial do Município. Fortaleza, 11 set. 2002a.

. Plano estratégico de Fortaleza. Fortaleza, 2002b.

. Fortaleza em números. Fortaleza, 2003.

. Legfor: projeto de revisão e atualização da legislação urbanística de Fortaleza. Fortaleza, 2004.

(SEDAS). Estatísticas de educação. Fortaleza, 2003.

(SEFIN). Sistema de arrecadação municipal. 2002/2003.

(SEPLA). Estudo socioeconômico, urbanístico e ambiental das sedes de Paran-

$\overline{\text { gaba e }}$ Messejana. Fortaleza, 2003.

GÜELL, J. M. F. Planificación estratégica de ciudades. Barcelona: Gustavo Gili, 1997. 
IBGE. Censo demográfico 2000. Rio de Janeiro, 2001.

IPECE. Anuário estatístico do Ceará 2002/2003. Fortaleza, 2004.

IPLANCE. Anuário estatístico do Ceará 1998/1999. Fortaleza, 2000.

KAPLAN, R. S. Strategic performance measurement and management in nonprofit organizations. Nonprofit Management and Leadership, v. 11, n. 3, p. 353-370, Spring 2001.

KAYSER, B. A região como objeto de estudo da geografia. In: GEORGE, Pierre et al. A geografia ativa. São Paulo: Difusão Europeia do Livro, 1966. p. 281-324.

PNUD. Desenvolvimento humano e IDH. Disponível em: < www.pnud.org.br/idh> . Acesso em: 30 abr. 2004.

PORTER, M. E. Competitive strategy. New York: The Free Press, 1980.

. Competição. On competition: estratégias competitivas essenciais. Rio de Janeiro: Campus, 1999. . Gestão estratégica. Exame, ed. 735, p. 106-114, 7 mar. 2001.

RIO GRANDE DO SUL. Secretaria de Coordenação e Planejamento. Estados comparados por funções do orçamento. Relatório 2005. Disponível em: <www.scp.rs.gov. br/estadoscomparados >. Acesso em: 7 jan. 2006.

SAWHILL, J.; WILLIAMSON, D. Measuring what matters in nonprofits, $n$. 2. The McKinsey Quarterly, 2001.

SCHERER, F. M.; ROSS, D. Industrial market structure and economic performance. 3. ed. Boston: Houghton Mifflin, 1990. 1996. 435p.

. Industry structure, strategy and public policy. New York: Harper Collins,

SEBRAE. Perfil do empreendedor e do cliente do Centro de Fortaleza. Fortaleza: CDL, 2004.

SINE/IDT. Rais/Caged. Fortaleza, 2002/2003.

ZANCHETI, S. M. Revitalização do Centro Histórico do Recife: uma experiência de gestão com a iniciativa privada. Disponível em: <www.urbanconservation.org $>$. Acesso em: 15 fev. 2004. 